LA-UR-00- $5 \hat{P}$
October 2000

THE HEATPIPE-OPERATED MARS EXPLORATION REACTOR (HOMER)

by

David I. Poston

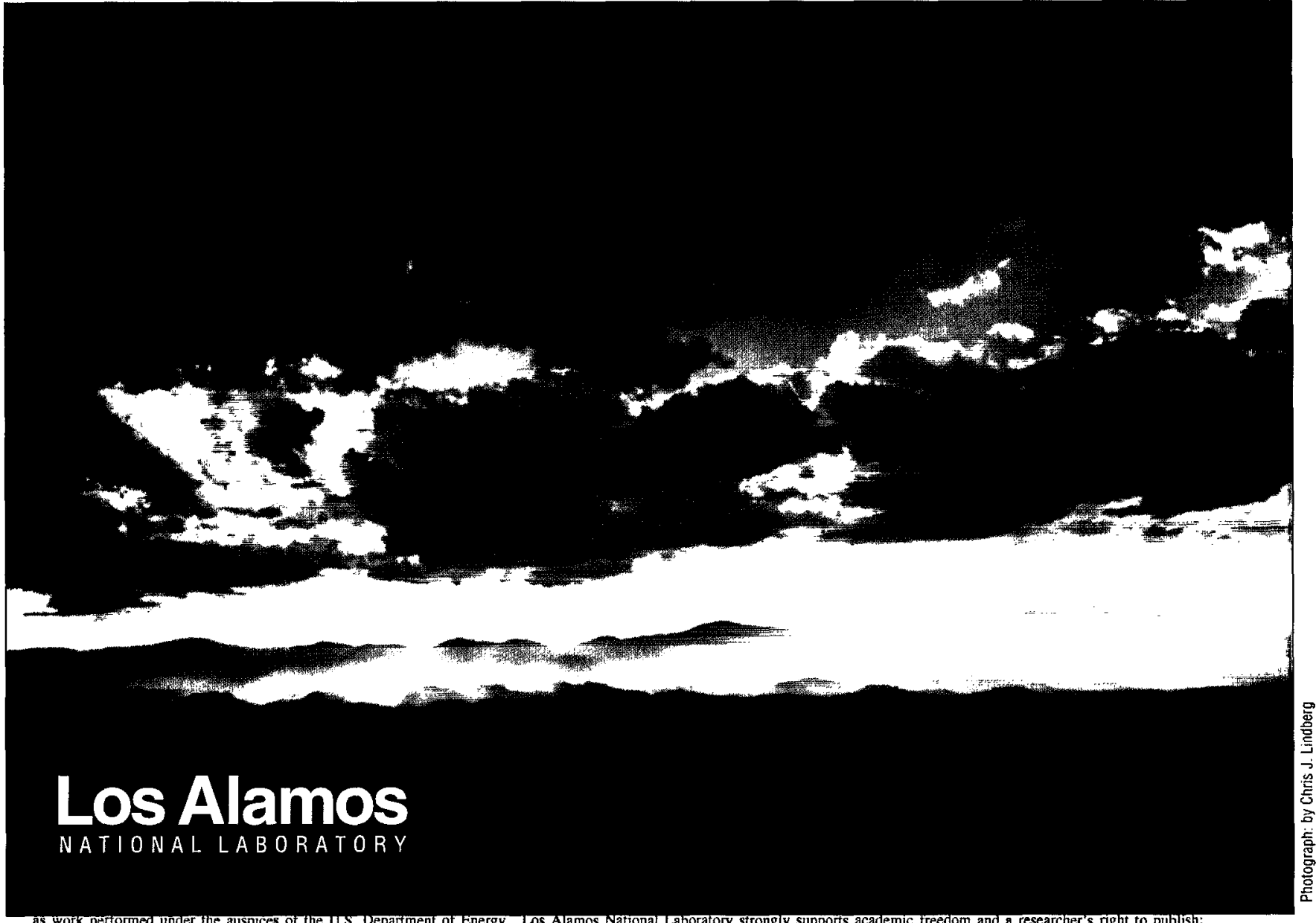

as work pertomed under the auspices of the Us Department of Energy. Los Alamos Nationgl Laboratory strongly supports academic freecom and a researcher's night to publish therefore, the Laboratory as an institution does not endorse the viewpoint of a publication or guarantee its technical correctness. 


\section{DISCLAIMER}

This report was prepared as an account of work sponsored by an agency of the United States Government. Neither the United States Government nor any agency thereof, nor any of their employees, make any warranty, express or implied, or assumes any legal liability or responsibility for the accuracy, completeness, or usefulness of any information, apparatus, product, or process disclosed, or represents that its use would not infringe privately owned rights. Reference herein to any specific commercial product, process, or service by trade name, trademark, manufacturer, or otherwise does not necessarily constitute or imply its endorsement, recommendation, or favoring by the United States Government or any agency thereof. The views and opinions of authors expressed herein do not necessarily state or reflect those of the United States Government or any agency thereof. 


\section{DISCLAIMER}

Portions of this document may be illegible in electronic image products. Images are produced from the best available original document. 


\title{
The Heatpipe-Operated Mars Exploration Reactor (HOMER)
}

\author{
David I. Poston \\ Los Alamos National Laboratory, 505-667-4336, poston@lanl gov
}

\begin{abstract}
The Heatpipe Power System (HPS) is a near-term, low-cost, space fission power system that has been under development at Los Alamos National Laboratory (LANL) for 5 years. The goal of the HPS project is to devise an attractive space fission system that can be developed quickly and affordably. The primary ways of doing this are by using existing technology and by designing the system for inexpensive testing. If the system can be designed to allow highly prototypic testing with electrical heating, then an exhaustive test program can be carried out inexpensively and quickly and thorough testing of the actual flight unit can be performed which is a major benefit to reliability. Over the past 4 years, LANL has conducted three HPS proof-of-concept technology demonstrations each has been highly successful. The Heatpipe-Operated Mars Exploration Reactor (HOMER) is a derivative of the HPS designed especially for producing electricity on the surface of Mars. The key attributes of the HOMER are described in this paper, as well as a $20-\mathrm{kWe}$ point design, system scalability, and the current technology status.
\end{abstract}

\section{INTRODUCTION}

Space fission power systems can enhance or enable ambitious lunar and Martian surface missions, as well as many solar-system and deep-space science missions. Research into space fission power systems has been ongoing (at various levels) since the 1950 s, but to date the United States (US) has flown only one space fission system, SNAP$10 \mathrm{~A}$, in 1965. Cost and development time have been significant reasons why space fission systems have not been used by the US. High cost and long development time are not inherent to the use of space fission power; however, these factors are inherent to any program that tries to advance technology too far. Nearly all US space fission power programs have attempted to field systems capable of high power and/or long lifetime, even though more modest systems had not yet been flown. All of these programs have failed to fly a space fission system.

Martian surface power is an obvious application for space fission systems. At higher power levels, solar power becomes impractical because of the size of the array, distance from the sun, dusty environment, and the difficulty of deployment; also, fission systems are independent of seasonal and geographic sunlight issues. Fission systems currently are being considered for robotic missions proposed for later this decade. The system will need to be very compact and lightweight and provide between 1 and $20 \mathrm{kWe}$ of power. This low-power system will be a precursor to a higher-power system that could be used for surface power on a manned Mars mission. The manned surfacepower system might provide between 50 and $250 \mathrm{kWe}$ and will be used for life support, operations, in-situ propellant production, scientific experiments, high-intensity lamps for vegetable growth, etc. On Mars, a solar array would require the area of several football fields to produce this level of power output.

The Heatpipe Power System (HPS) is a potential, near-term, low-cost space fission power system that could be used for Martian surface power. The proposed HPS designs are composed of independent modules, and all components use existing technology and operate within the existing database. The HPS has relatively few system integration issues; thus, most engineering issues can be solved with module tests. In addition, the HPS is designed to allow prototypic system testing with resistance heating. Three ongoing programs aim to prove that the HPS is a viable, near-term, low-cost space fission system, and the results to date have been very encouraging. Figures 1 and 2 show some of the hardware that has been developed by these programs. The Heatpipe-Operated Mars Exploration Reactor (HOMER) is a derivative of the HPS designed especially for producing electricity on the surface of Mars. 


\section{GENERAL ATTRIBUTES OF THE HOMER}

The HOMER contains stainless-steel (SS)-clad uranium dioxide $\left(\mathrm{UO}_{2}\right)$ fuel pins that are structurally and thermally bonded to SS/sodium ( $\mathrm{Na}$ ) heatpipes. Heat is conducted from the fuel pins to the heatpipes, which then carry the heat out to an ex-core power conversion system. The following paragraphs describe the important attributes of the proposed HOMER. A previous paper contains more detail on using the HPS concept for surface applications and evaluating the designs (Poston, 2000).

Low Development Time and Cost: The HOMER minimizes development time and cost primarily by using existing technology (i.e., no technology development programs) and by designing the system for inexpensive electrical testing (thus minimizing or eliminating nuclear testing, except for zero-power criticals). In addition, all HOMER development and testing can be performed in existing facilities. Nearly all core components are SS; therefore, material and fabrication costs will be low. The system is designed so that the fuel can be added to and removed from the core very easily; this will allow easier and less-costly transport and storage of the system (and allows the potential for in-space fueling). Finally, development time and cost should be low because overall the HOMER is a very simple, modular system.

Safety: Safety is the first consideration when designing any HPS system. The HOMER is designed to be passively safe in all credible launch or reentry accidents no operations are required after launch to make the reactor ready for startup (no safety rods, removable poisons, or post-launch fueling). This is done by permanently placing boron carbide in the core and taking advantage of the neutron spectral shift during water immersion scenarios. The reactor remains subcritical even if the entire core void is flooded with water (including heatpipe and fuel-pin gaps), and the system is surrounded by wet sand this is the worst-case scenario for a water immersion accident. Passive subcriticality adds $\sim 80 \mathrm{~kg}$ of mass to the reactor, but it simultaneously provides absolute safety and the most reliable system operation. Safe and reliable alternatives to eliminate this mass penalty currently are being evaluated. The HOMER also has passive removal of decay heat and is essentially nonradioactive before operation.

Reliability and Lifetime: Reliability is second only to safety in the design of HPS systems. No potential singlepoint failures exist in the HOMER (and possibly none in the entire system, depending on the balance of plant configuration). The HOMER is cooled by heatpipes; therefore, the system does not require a hermetically sealed vessel or any components that are required by a pumped-loop system. This provides very high reliability and allows simplified and thorough nonnuclear testing of prototypes and of the actual flight unit, which further enhance reliability. The thermal requirements on the heatpipes are very moderate; the maximum axial and radial heat fluxes are an order of magnitude below existing technology limits. Similar heatpipes have operated to longer lifetimes and higher fluences than required by this application. Several other factors contribute to high system reliability and

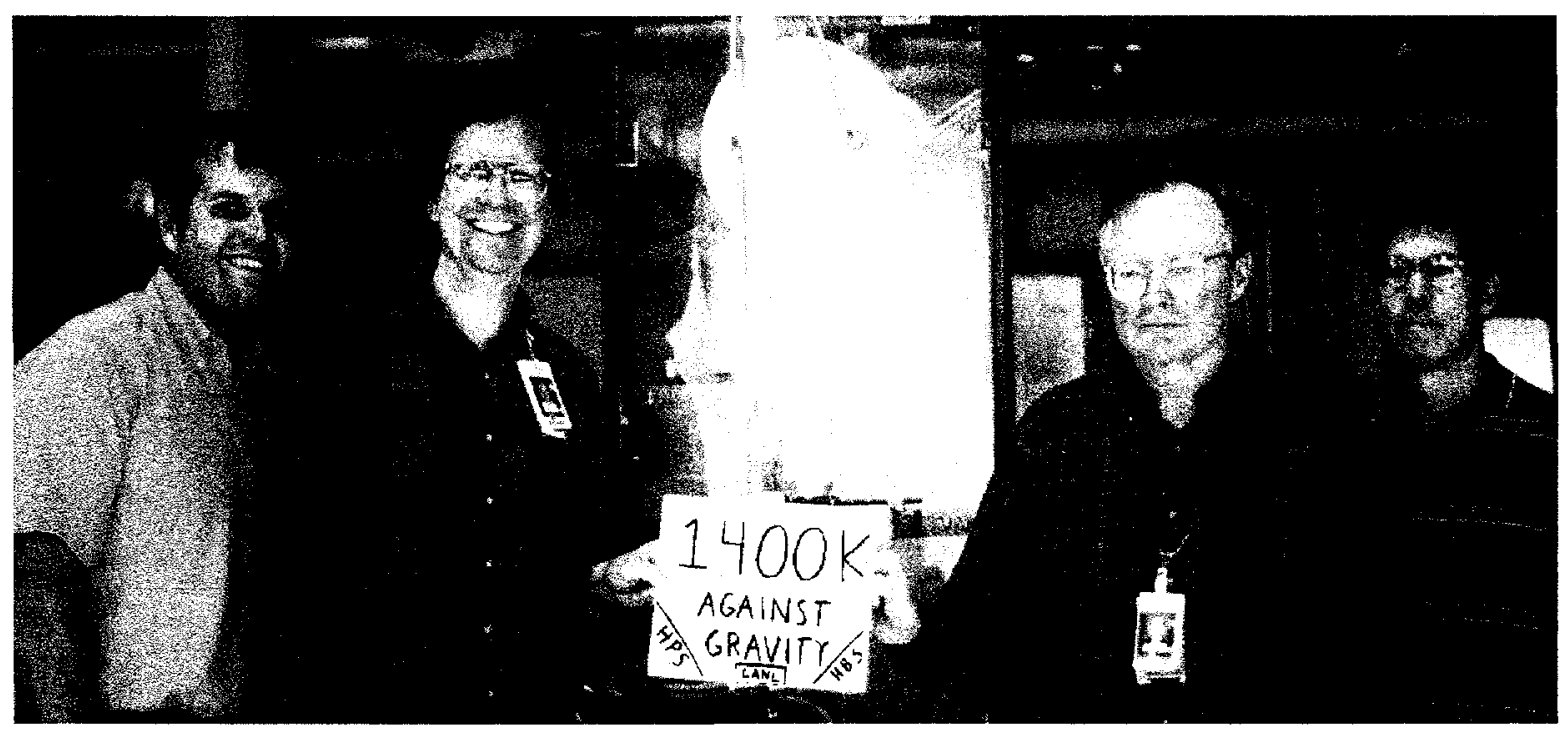

FIGURE 1. Testing of the First Mo/Li Heatpipe November 1996. 
lifetime: low core temperature, low fuel burnup, low fluence, proven fuel form, modularity, and the overall system simplicity. A highly reliable system such as HOMER is even more important in future manned missions where reliability is tantamount to safety.

Thermal Performance: The HOMER is designed with a large thermal margin. The maximum reactor power is determined by material temperature limits (heatpipe, burnup, and fluence limits are not approached). For HOMER, the limiting requirement is that the peak SS temperature remains below $1250 \mathrm{~K}$ (during nominal operation, the peak SS temperature is only $\sim 1120 \mathrm{~K}$ ). The power level of an HPS is limited largely by the conductivity and maximum operating temperature of the clad material (which is why refractory cores have much higher power levels than superalloy cores). Hopefully, a well-established material can be found that has a higher conductivity and operating temperature than SS and meets all other requirements. The HOMER is designed to produce rated power even if the worst-case heatpipe has failed and there is no contact between the failed module and other modules. Full power can be provided with multiple heatpipe failures if they are not adjacent if they are adjacent, then the power will have to be lowered to avoid reaching temperature limits. Thermal performance of the entire system can be well established with resistance-heated testing.

Nuclear Performance: The HOMER is designed with a robust, well-proven clad/fuel form $\left(\mathrm{SS} / \mathrm{UO}_{2}\right)$. The cladthickness-to-pin diameter ratio is high (0.05), and the fuel is loaded at $90 \%$ theoretical density. The burnup and fluence is extremely low and is well within the existing database. Other clad/fuel options could provide significantly better performance and lower mass, but this option should provide the highest reliability, least technical risk, and lowest cost. As mentioned above, heatpipes similar to those used have been operated successfully at much higher fluences. No other components within the core exist to which radiation damage will be an issue (no hermetic seals, tightly toleranced gaps, etc.). Subsystem components, power conversion, control drives, electronics, etc., will have to be shielded as necessary. The HOMER is designed with a cold-clean $\mathrm{k}$-eff of 1.03 , and the temperature defect and burnup reactivity are each less than $1 \%$. The HOMER is a fast reactor; the temperature reactivity feedback is small (and negative), and the neutron lifetime is relatively short, but upon initial examination it appears that reactor control should not be too difficult. Zero-power criticals will be required to verify all nuclear characteristics that pertain to safety.

Mechanical Performance: Many SSs $(316,304$, etc.) are very well characterized, and fabrication and welding are well understood. The biggest mechanical performance issue of the HOMER results from its operation at high temperature in a nuclear environment. The strength of SS is significantly lower at the temperatures in which the HOMER operates $(950$ to $1250 \mathrm{~K})$. This lowering in strength in itself should not be a problem and can be investigated with nonnuclear testing. Nuclear irradiation normally will make SS stronger but can significantly decrease ductility; therefore, it is the combination of reduced strength and ductility that will require particular attention during the design process. Fortunately, stresses and fluences are low in the HOMER design 5 years at full power produces a peak fluence of $\sim 3^{\circ} x^{\circ} 10^{21^{\circ}} \mathrm{n} / \mathrm{cm}^{2}$. Ideally, the HOMER would be designed not to exceed yield strength under any conditions (electrically heated testing could be used to verify this). Then it could concluded with confidence that yield would not be reached at any point during the system life, and ductility would not be an issue. If for some reason strength and ductility loss are a major issue, a different material will have to be considered.

Effects of Mars Atmosphere: The HOMER is designed not only to survive, but to take advantage of the Martian atmosphere. SS is used for all reactor components in contact with the atmosphere, and the reactor does not need to be placed in a hermetically sealed environment (although some type of protection may be required to prevent dust buildup). Exposure to $\mathrm{CO}_{2}$ improves thermal performance by carburizing/oxidizing the SS (increasing emissivity) and by providing a thermal conduction path in gaps where pins/heatpipes do not have good thermal contact. The atmosphere also can be utilized as a heat sink if a flowing $\mathrm{CO}_{2}$ radiator is used. A paper by Lipinski

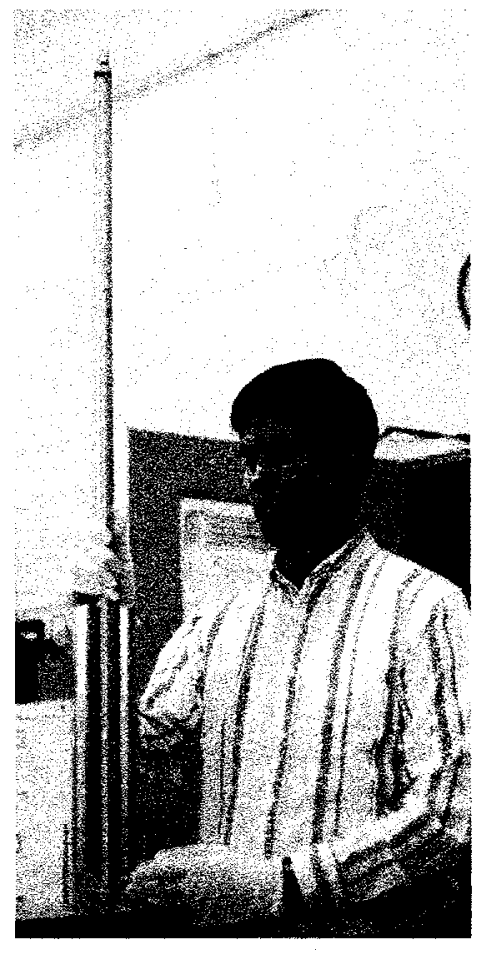

FIGURE 2. Completed HPS Module. 
et. al. describes an innovative radiator design that rejects heat to the atmosphere (Lipinski, 1999). Martian gravity could be used to aid in heatpipe performance and possibly allow the efficient use of a Rankine conversion cycle. The atmosphere and/or other indigenous materials also can be used to reduce shielding mass. A paper by Houts et. al. describes various options for using indigenous materials for shielding, including the use of liquefied or frozen $\mathrm{CO}_{2}$ from the Martian atmosphere (Houts, 1999). Problems with dust clogging up or coating control drives and other components may be a problem, as it always will be with all systems deployed on Mars. Another potential problem caused by the atmosphere could be embrittlement of the SS caused by carburization. Carburization generally causes the same property changes as irradiation (increase in strength and decrease in ductility), so by addressing one issue we may address the other. This actually could be an advantage because carburization effects can be tested in a nonnuclear manner. When the system is examined in more detail, a well-established material other than SS could be chosen that optimizes power, mass, cost, and reliability (strength, ductility, corrosion resistance, radiation damage, etc.).

Thermal Power Scalability: The thermal power of most HPS reactors is determined by material temperature limits (at very high powers the performance starts to become limited by heatpipe or fuel burnup limits). Ways to increase the power are using higher temperature materials, lowering the heatpipe temperature, using a higher heatpipe-tofuel-pin ratio, using smaller diameter heatpipes/fuel pins, relaxing the reliability requirements, and simply increasing the overall size. Using higher-temperature materials in the HOMER will be difficult because of the corrosive potential of the atmosphere (a hermetically sealed vessel may be required). Lowering the heatpipe design temperature will allow higher thermal power (provided that the heatpipes can handle the required throughput), but it will also decrease conversion efficiency this is a design optimization that must be made. The HOMER already has a high heatpipe-to-fuel-pin ratio, so this option is probably not practical. Relaxing reliability will depend on the mission, and increasing the overall size is not a very mass effective way of increasing power. This leaves the option of using smaller heatpipes and fuel pins. This method gives the HOMER a practical thermal power range of 25 to $500 \mathrm{kWt}$. If refractory metals can be used, this raises the upper limit to $>1 \mathrm{MW}$. Certainly much higher powers can be delivered by increasing the size of the reactor, or clustering reactors, but in these cases the fractional increase in mass approaches the fractional increase in power.

\section{A 20-kWe HOMER POINT DESIGN}

Reactor Core: The reactor is designed with all of the attributes mentioned above. The number of heatpipes and the diameter of the heatpipes and fuel pins are determined by the criticality and thermal requirements. This reactor is designed to deliver $125 \mathrm{kWt}$ to the power conversion system at a temperature of $1000 \mathrm{~K}$. The core has 57 heatpipes, 152 fuel pins, and $8 \mathrm{BeO}$ pins, each with an outer diameter of $1.7 \mathrm{~cm}$ and a wall thickness of $0.85 \mathrm{~mm}$. The heatpipes are SS with an SS mesh/annular wick and sodium working fluid. The heatpipes extend out of the core $50^{\circ} \mathrm{cm}$ (this length will depend on how the heat is transported to the power conversion system). The length of the core region (including a 4-cm BeO pellet axial reflector on each end) is $54 \mathrm{~cm}$, and the outer diameter of the $\mathrm{BeO}$ radial reflector is $45 \mathrm{~cm}$. The fuel is $90 \%$ theoretical density $\mathrm{UO}_{2}$ with an enrichment of $97 \%\left(128 \mathrm{~kg} \mathrm{of} \mathrm{UO}_{2}\right)$. The core interstitials are filled with $96 \% \mathrm{SS}, 4 \% \mathrm{~B}_{4} \mathrm{C}$ tricusps that help achieve passive core shutdown in water immersion events. The total mass of this reactor is $385 \mathrm{~kg}$, including radial reflector, primary heatpipes, baffle, top/bottom support plates, tricusps, and slats. This mass can be reduced significantly by changing the fuel to UN, changing the general safety approach, or removing some thermal conservatism, but these changes would increase technical risk. A cross-section of the reactor is provided in Figure 3.

Instrumentation and Control: Two primary options for reactivity control are external rotating control drums or sliding/pivoting reflector segments. Internal control/safety mechanisms are not required in reactors with high radial reflector worth such as HOMER, and they would add considerable mass and complexity. Control drums are specified for the baseline system, which should provide the best option for reliability and safety; the potential advantage of a sliding reflector is a reduction in mass. The total mass for instrumentation and control should be $\sim 50^{\circ} \mathrm{kg}$ (reflectors and drums are included in the reactor mass).

Power Conversion and Management: Several choices are available for power conversion. This reactor concept is compatible with any ex-core conversion type: thermoelectric, thermionic, AMTEC, Brayton, Stirling, or Rankine. Recent progress in Stirling conversion makes it a good initial choice for the baseline design. Discussions with Stirling Technologies Co. indicated that a $20 \%$ efficient 5 - to $6-\mathrm{kWe}$ Stirling engine can be produced at $16 \mathrm{~kg} / \mathrm{kW}$ with existing technology (this includes power conditioning). Five 5-kWe engines could be used at a total mass of 


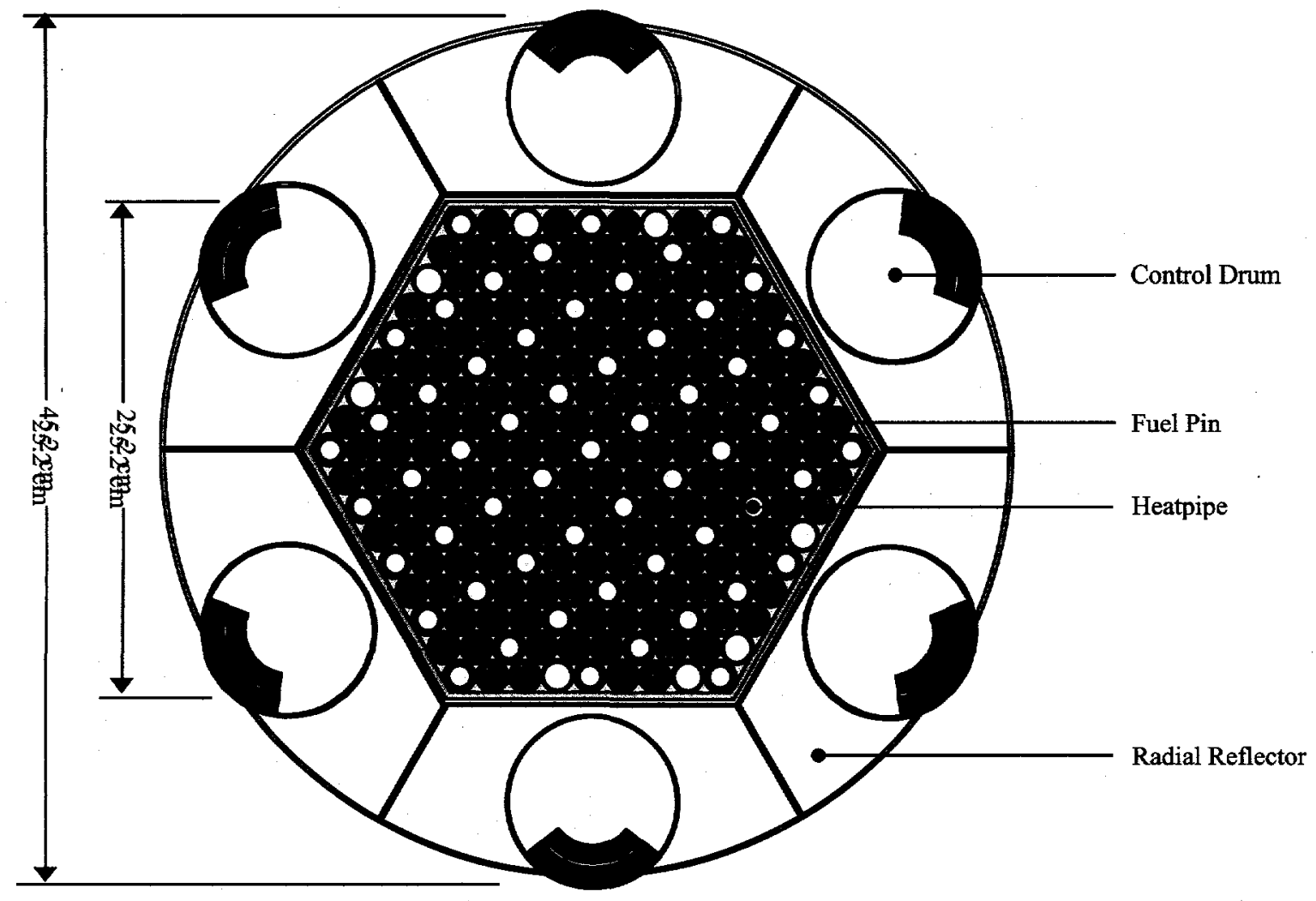

FIGURE 3. Cross-Section of the 125-kWt HOMER Core.

$400 \mathrm{~kg}$. Producing $20 \mathrm{kWe}$ would require four of the five engines to be operating if the reactor is producing $100 \mathrm{kWt}$ ( $80 \%$ of rated power). An important design issue that must be addressed is the transfer of heat from the primary (core) heatpipes to the Stirling engine heads. Perhaps the most optimum configuration would be to have the primary heatpipes transfer heat to the secondary heatpipes via a conductive block, whereas the secondary heatpipes would deliver power directly to the Stirling heads. Thus, the secondary heatpipes would travel around and/or through the shielding. Depending on the configuration, the heat exchanger and secondary heatpipes might weigh $\sim 50 \mathrm{~kg}$. If this configuration is not optimal, then it could be possible to have the primary heatpipes connect directly to the engines or perhaps would require using a different heat exchanger than a conductive block. Although the Stirling mass estimate includes power conditioning, there will still be some components required to condition and distribute the electricity further. These components may add another $25 \mathrm{~kg}$.

Radiation of Excess Power: Two primary options are available for removing excess thermal energy. The first is a standard, stowed deployable radiator, and the second is a radiator that uses the flowing Martian atmosphere to remove heat. The convective radiator could offer mass and volume savings, but it does not have the technology base of the deployable radiator. For now, the deployable radiator is the baseline choice: the panels would be deployed vertically to avoid dust collection. Given a specific mass of $4 \mathrm{~kg} / \mathrm{m}^{2}$, a rejection temperature of $473 \mathrm{~K}$, and an effective emissivity of 0.9 , the radiator mass required to reject $80 \mathrm{kWt}$ would be $125 \mathrm{~kg}$ (area $=31^{\circ} \mathrm{m}^{2}$ ). The components required to couple the Stirling engines and the radiator may add $\sim 20 \mathrm{~kg}$.

Shielding: It is impractical to provide a mass estimate for shielding without more details of the mission requirements. In addition, there are so many potential options to provide indigenous shielding that a detailed study must be performed to determine which one is best for the mission. These options include bringing all shielding material from Earth, using Martian dirt and rock (digging holes, stacking rocks, etc.), using Martian topography (moving the reactor into a crater or driving behind a ridge), using distance (moving the reactor some distance away), using the Martian atmosphere (liquefying or solidifying Martian $\mathrm{CO}_{2}$ ), or using any combination of these. In all cases, some built-in shielding will be required to protect reactor subsystem components. For the HOMER this 
may require $\sim 100 \mathrm{~kg}$, depending mostly on the radiation resistance and size of the Stirling engines. Depending on operational requirements and whether the mission is robotic or crewed, the mass of extra shielding and/or the equipment required to utilize indigenous shielding could range from hundreds to thousands of kilograms.

Estimated Mass of a 20-kWe HOMER: The following estimate is rough and intended to be conservative. The reactor mass is relatively well determined because of the detailed work that has been done on the reactor design. The balance-of-plant mass is estimated based on the paragraphs above more work must be done to improve this estimate. A contingency of $20 \%$ should be very conservative because the HOMER is a simple system with very few system integration requirements, and thus, there should not be many unforeseen components (most of the structure is contained in the component masses). Also, several options could be used to lower the mass significantly: using UN fuel, using higher temperature materials, utilizing a different safety approach, using more efficient power conversion, etc., but these options could have other significant drawbacks. All options will have to be considered seriously when fully evaluating the system.

$\begin{array}{lr}\text { Reactor } & 385 \mathrm{~kg} \\ \text { Instrumentation and Control } & 50 \mathrm{~kg} \\ \text { Power Conversion and Management } & 475 \mathrm{~kg} \\ \text { Radiator } & 145 \mathrm{~kg} \\ \text { Shielding (for Subsystem Components) } & 100 \mathrm{~kg} \\ \text { Contingency (20\%) } & 230 \mathrm{~kg} \\ \text { Total (Minus Mission-Specific Shielding) } & 1385 \mathrm{~kg}\end{array}$

Scalability of the Baseline HOMER Concept: Rough mass estimates at various powers were obtained using the same methodology as that used above for the $20-\mathrm{kWe}$ design. Scaling was performed based on how each component depends on reactor size and power level. In this case, the $20 \%$ contingency was absorbed into each component; this allows better comparison of the contribution of each component to the mass. A bar graph in Figure 4 shows the mass of each component at various power levels. Figure 5 shows the power vs mass on a linear scale,

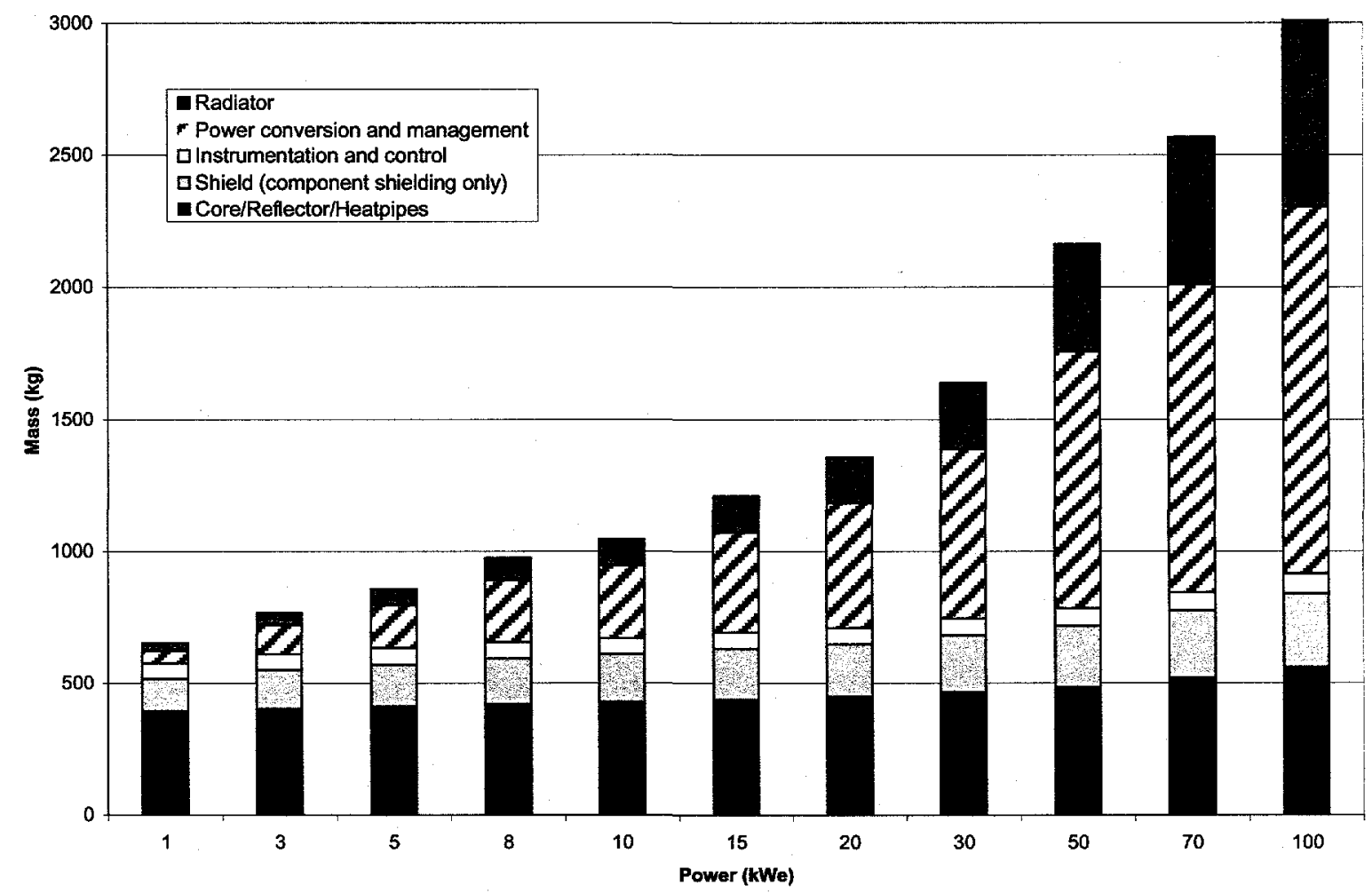

FIGURE 4. Estimated Mass Breakdown of the HOMER at Various Powers (20\% Contingency Included in Each Component Estimate). 
and it also shows what a higher-tech HPS design might be able to achieve. This design uses UN instead of $\mathrm{UO}_{2}$ fuel, molybdenum clad instead of SS, and Brayton conversion instead of Stirling (it is assumed that the Brayton system has a $35 \%$ conversion efficiency and a radiator temperature of $573 \mathrm{~K}$ ). Each of these factors can increase the specific power of the system but will probably add technical risk and cost to the system development. This does not say that Brayton in itself is necessarily a higher risk/cost than Stirling, only that its integration into an HPS system is. Figure 5 shows that as power increases, the advantage of the Brayton system becomes larger. It is possible that at low powers $(<5 \mathrm{kWe})$, a static power conversion system [thermoelectric, thermionic, or alkali metal thermal-toelectric conversion (AMTEC)] could be optimal for certain applications.

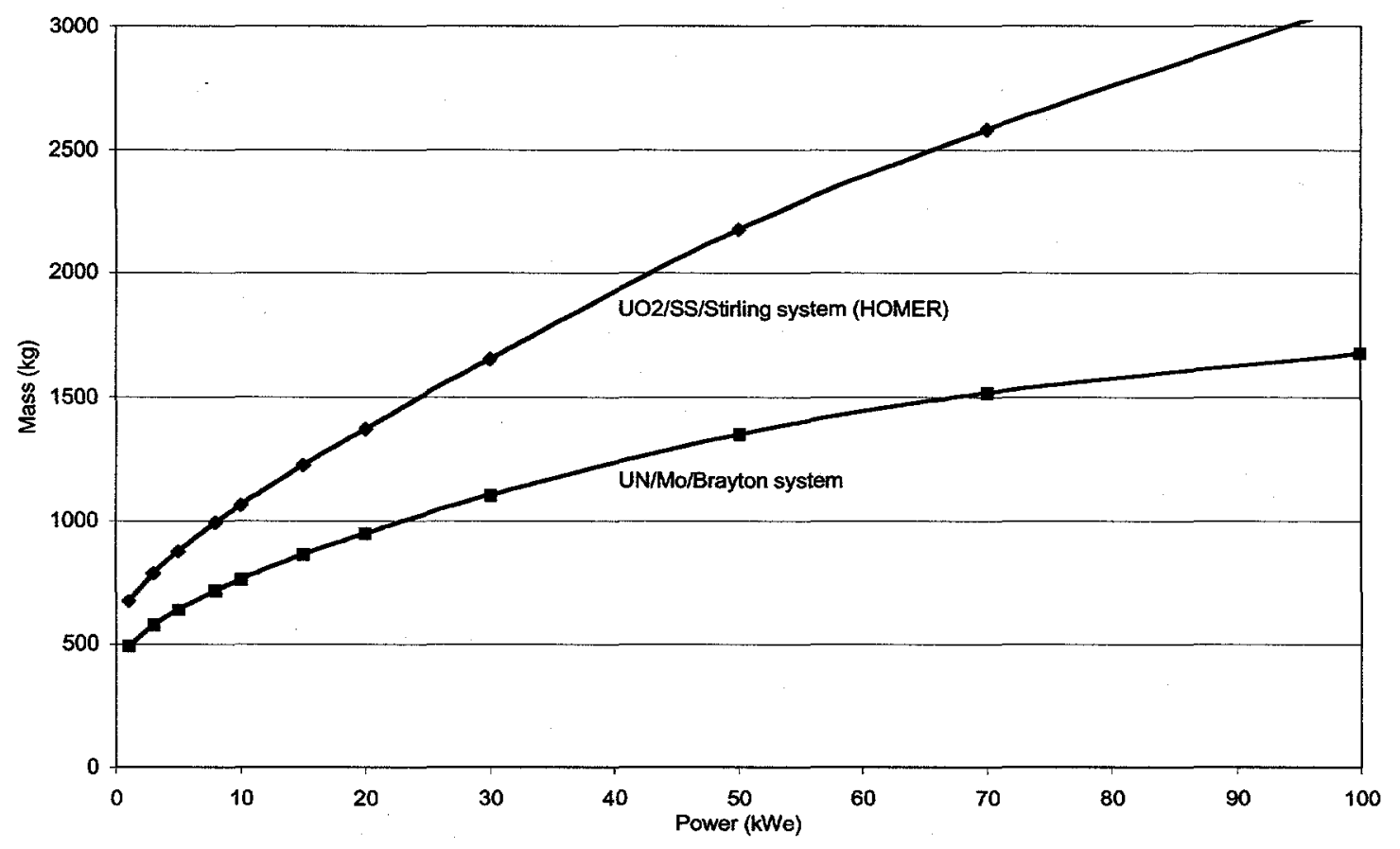

FIGURE 5. Estimated Mass Breakdown of HOMER at Various Powers.

\section{TECHNOLOGY DEMONSTRATION STATUS}

Three hardware-based proof-of-concept demonstrations have been initiated by Los Alamos National Laboratory (LANL). The first program tested a molybdenum HPS module with a high-temperature $\mathrm{Mo} / \mathrm{Li}$ heatpipe. This module was successfully tested to $4 \mathrm{KWt}$ with a heatpipe temperature of $1400 \mathrm{~K}$, and the module was successfully shut down and restarted nine times. In the second hardware program, a tungsten module was constructed with a smaller $\mathrm{Mo} / \mathrm{Li}$ heatpipe. This module was used to demonstrate bimodal capability simultaneously delivering power through the heatpipe and power to hydrogen flowing through the core. The third and most significant program is now near completion the HPS full-core demonstration (demo). The HPS full-core demo has built 12

SS modules, which if fueled with $\mathrm{UO}_{2}$ would represent a critical core. This demo will test the thermal performance of the 30-kWt core with resistance heaters and demonstrate that the core can survive the thermal stresses. If successful, the HPS full-core demo will provide high confidence that a 125-kWt working fission system (i.e., the HOMER) can be built quickly and affordably. The majority of testing of the HPS full-core demo is being conducted at the National Aeronautics and Space Administration (NASA) Marshall Space Flight Center (MSFC); preliminary test results have been very positive. A photograph of a mockup core test is shown in Figure 6 . 


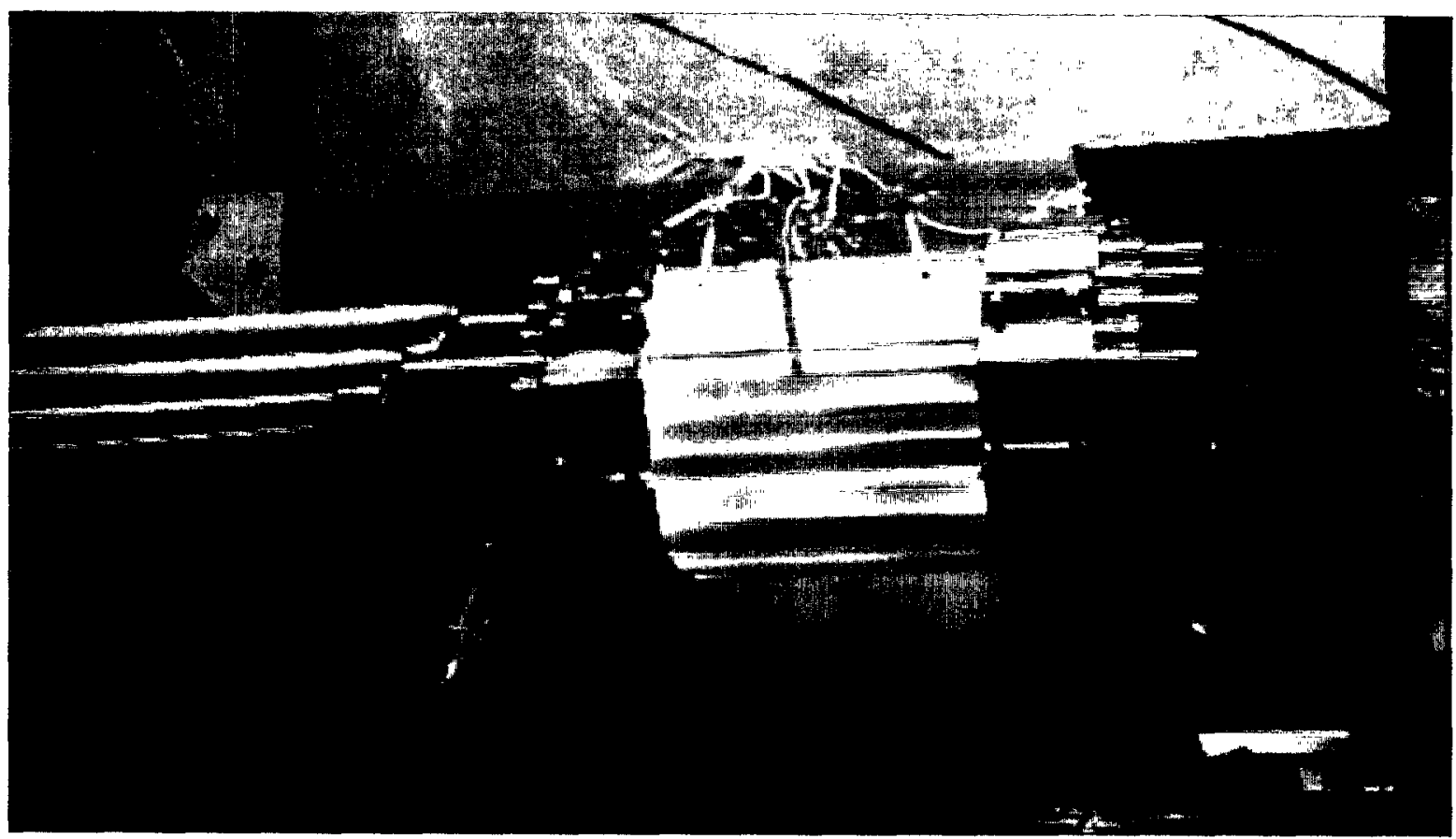

FIGURE 6. Testing of a Mockup HPS Demo Core at $1100 \mathrm{~K}$ at NASA MSFC.

\section{CONCLUSIONS}

The HOMER is a robust, low technical risk fission system that can provide electric power on the surface of Mars. This system is based on the Heatpipe Power System (HPS) concept that has been under development for several years at LANL. The HOMER is designed to be a near-term, low-cost system by using existing technology, designing the system for prototypic electrically heated testing, and keeping the system simple. Hardware testing currently is being conducted that, if successful, will help verify that the HOMER is a viable and attractive option for Mars surface power.

\section{ACKNOWLEDGMENTS}

The authors wish to thank the NASA MSFC and the LANL Center for Space Science and Exploration for their support.

\section{REFERENCES}

Houts, M. G., Poston, D. I., Trellue, H. R., Baca, J. A., and Lipinski, R. J., "Planetary Surface Reactor Shielding Using Indigenous Materials," Space Technology and Applications International Forum-1999 (STAIF-99), edited by Mohamed S. El-Genk, AIP Conference Proceedings 458, 1999, pp. 1476-1479.

Lipinski, R. J., Wright, S. A., Lenard, R. X., and Harms, G. A., "A Gas-Cooled Reactor Surface Power System," Space Technology and Applications International Forum-1999 (STAIF-99), edited by Mohamed S. El-Genk, AIP Conference Proceedings 458, 1999, pp. 1470-1475.

Poston, D. I., Voit, S. L., Reid, R. S., and Ring, P. J., "The Heatpipe Power System (HPS) for Mars Outpost and Manned Mars Missions," Space Technology and Applications International Forum-2000 (STAIF-00), edited by Mohamed S. El-Genk, AIP Conference Proceedings 504, 2000, pp. 1327-1334. 